\title{
H.P. Lovecraft, the master of the horror a schizotypal?
}

\author{
C. Vera Scamarone \\ Psicointegral, Psychiatry, lima, Peru.
}

\section{Introduction:}

Howard Phillipe Lovecraft (1890 - 1937) actually, is one of the most influent writers in horror fiction literature. His tales are filled of references about an unnamed horror, unspecific words with uncompleted sense, a destiny, and guilty. All these things make that writer be an influence for many arts: other writers, cinema, television, games, etc. But his life had many illness topics, and possible a mental illness.

\section{Objectives:}

Evaluate if in Lovecraft's narrative there are elements that allow us an approximation to your mental health.

Many elements in the Lovecraft narrative are related with his mental health. The perform of his life, around his mother, his grandfather, and a psychotic event of his father possibly are related with the apparition of horror in his tales.

\section{Methods:}

Review of twenty books, between novels, tales and two biography's authorized. Review of the criteria diagnostics of CIE 10 manual.

\section{Results:}

Lovecraft has many patterns of a castrated and schizoid behavior. The unnatural fear to the humanity. He had two depressive episodes. Two letters gave highlights: 1)He write about his suicide intention. 2) Irritability.

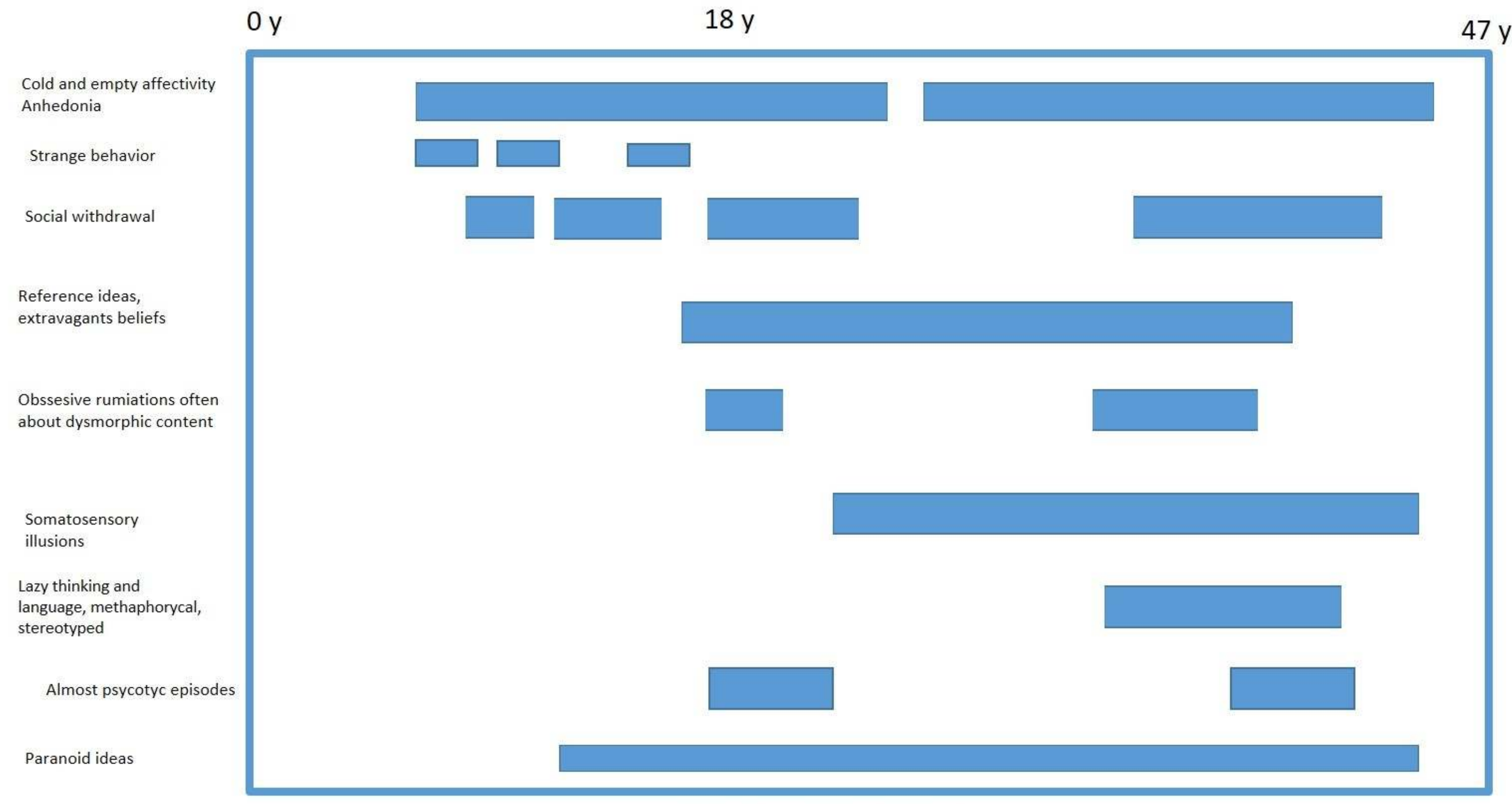

Symptoms during his life 